\title{
$X V$. Some experiments on the diffusion of substances in solution
}

\section{Spencer Umfreville Pickering M.A. F.R.S.}

To cite this article: Spencer Umfreville Pickering M.A. F.R.S. (1893) XV. Some experiments on the diffusion of substances in solution, Philosophical Magazine Series 5, 35:213, 127-134, DOI: $10.1080 / 14786449308620341$

To link to this article: http://dx.doi.org/10.1080/14786449308620341

曲 Published online: 08 May 2009.

Submit your article to this journal $[\pi$

Џ Article views: 2

Q View related articles $₫$ 
XV. Some Experinents on the Diffusion of Substances in Solution. by Spencer Umfreville Pickering, M.A., F.R.S.*

$7 \mathrm{THE}$ following determinations of the comparative rates of diffusion of various non-electrolytes were intended to be preliminary to a more extended investigation, but, as I do not see my way at present to continue the work, I think it. well to put on record those results which have so fir been obtained.

Osmotic pressure is held to be due simply to the gaseous impact of the dissolved substance, and is therefore proportional to the number of molcules per unit volume, the temperature being constant. Now, by Graham's law, the rate of diffusion of a gas should be, cateris paribus, inversely as the square root of its density, or of its molecular weight. Hence, at a given temperature and pressure the product of the molecular weight, $m$, by the square of the rate of diffusion, $v$, should be a constant. 'I The relative values for $v$ in the case of different bodies might be determined by simple diffusion-experiments if these could be conducted under perfect conditions: namely, the diffusing liquid remaining of a constant strength throughout, and the water into which diffusion is taking place remaining uncontaminated with the substance. The present results seem to show, either that the above supposition as to osmotic pressure is incorrect, or that the conditions obtainable in diffusion-experiments are very far from obtaining to ideal perfection ; for the values deduced for $m v^{2}$ are by no means constant, even in those cases where the substances behave normally as to their osmotic pressure, i.e. where the solutions of equal molecular strength give the same osmotic pressure, this latter being measured by the depression exercised by them on the freezing-point of the water in which they are dissolved.

The method adopted was that termed by Graham jardiffusion. The solutions under examination were placed in an open jar inside a large vessel of water, and the amount of substance which had diffused out of the former in a given time was ascertained by determining the strength of the remaining solution. The inner jars were beakers of a cylindrical form with ground flanges: they were ground also on the bottom, and rested on inverted ground-glass saucers placed in the centre of the large outer glass jars. Before being filled, each jar was placed in position and adjusted so

- Communicated by the Author. 
that the mouth of the inner jar should be exactly level. The jars were marked so that they could be replaced in the proper position after being filled. When filled they were closed by glass plates with rods attached to them, and then lowered inside the larger jars which had previously been filled with water. The glass plates were then removed very slowly and carefully. At the end of the time allowed for diffusion the plates were replaced on the jars, the latter were remored from the water and the strength of their contents determined. Both the large and small jars were filled two days before the latter were placed inside the former, in order that the temperature of the cellar in which the determinations were made might be attained; and after the inner jars had been placed in position a further period of five hours was allowed before the glass plates were removed, so that any disturbance of temperature which bad occurred in placing them in position might subside.

The capacity of the inner jars was 480 cubic centim., their internal diameter was 70 millim., and their internal height 125 millim. About three dozen of them were made, and of these the twelve which were found to be most uniform in size were used in the determinations. The extreme difference in the capacity of the largest and smallest of these twelve was $3 \cdot 3$ per cent., and the extreme difference of their superficies at the mouth was 3.8 per cent. The outer jars contained 12,000 cubic centim. of water, or twenty-five times the volume of the inner jars. The mouths of the jars were about midway between the surface and bottom of the water in the inner jars.

The strength of the solutions remaining in the jars at the end of the experiments was determined by means of their freezing-points. The solutions taken to start with were made up by weighing. The freezing-points of these, and also of weaker solutions obtained from them by dilution, were determined, and from these results the strength of any solution having a given freezing-point could be calculated. In order to minimize any errors due to possible irregularities of the freezing-points when plotted against composition, the solutions of known strengths, of which the freezing-points were determined, were selected so as to approach as nearly as possible to the strength of the solution left in the diffusion-jar.

The strength of the solutions taken was, as a rule, about 0.3 molecule to every 100 molecules of water, showing a depression of the freezing-point of water amounting to about $0^{\circ} \cdot 3$; about one third of the dissolved substance had diffused out by the end of the determination, the decrease in the 
freezing-point measured being thus about $0^{\circ} \cdot 1$. The water into which the diffusion had taken place would at the end of the experiment contain only about 4 molecules of the substance to every $100,000 \mathrm{H}_{2} \mathrm{O}$. These proportions had necessarily to be modified in several instances, and in such cases it was assumed that, in accordance with Graham's results (in support of which some of the present results may also be adduced), the rate of diffusion varied directly as the number of molecules present in a given volume of solution, or, more roughly, in a given weight of water.

The determinations were made in two separate series, marked (1) and (2) respectively in Table I., wbich contains the results. In the first series the temperature varied from $12^{\circ} \cdot 1$ to $15^{\circ} \cdot 3$, the time allowed being probably 18 days, the record of the exact timo having been unfortunately lost: in the second series the temperature was $16^{\circ} .0$ to $18^{\circ} \cdot 2$, and the time was 25 days. Varions steps were taken to estimate the magnitude of the probable errors. In the first place, the error due to any disturbance occurring in removing and replacing the glass plate from the inner jar was found to be inappreciable. A blank experiment in which these operations were performed showed that the solution of cane-sugar which the inner jar contained gave exactly the same freezing* point before and after the operations, $i$. $e$. within the estimation-figure of the thermometric reading, which was 0.05 millim. or $0^{\circ} .0005$. Secondly, in the first series duplicate determinations were made with each of the substances cane-sugar, acetic acid, and urea: the differences in the freezingpoints of the solutions obtained in ench pair were $0011^{\circ}$, $.0062^{\circ}$, and $\cdot 0026^{\circ}$ respectively, mean $0.0033^{\circ}$, or about 3 per cent. of the actual decrease measured, a quantity fully accounted for by the difference in size of the jars. Three per cent. in the actual decrease, however, represents only 1.24 per cent. in the proportional decrease (or actual decrease $\div$ mean freezing-point), which is the quantity which is taken to represent the rate of diffusion $v$; and an error of $1 \cdot 24$ per cent. here will represent an error of $2 \cdot 4$ per cent. on the values of the supposed constant $m v^{2}$. Thirdly, glycerine solutions of the same strength were used in both series, and so also were cane-sugar solutions of nearly the same strength : the relative values for $m \eta^{2}$ in the two series were $1: 2.586$ in the case of glycerine, and 1:2.567 in the case of cane-sugar, the difference between the two ratios amounting to only 0.3 per cent.

The results of the diffusion-experiments are given in Phil. Mag. S. 5. Vol. 35. No. 213. F'eb. 1893 . K 
Table I., the supplementary freezing-points nocessary for the calculation of the strengtbs of the final solutions being given in Table II. (In the case of cane-sugar and acetic acid the determinations used for this purpose have already been published, Berichte d. deutsch. chem. Gesell. xxiv. p. 3329.)

The values in the table refer to the weight of anhydrous substance, the water of crystallization, whenever present, having been allowed for. This water, in the case of alloxan, was found to be $3 \mathrm{H}_{2} \mathrm{O}$; whereas in the cases of gallic acid, tannin, and raffinose, 1,2 , and $5 \mathrm{H}_{2} \mathrm{O}$ were taken as being respectively present. The proportional decrease of freezingpoint or strength of the solution is the fraction which the actual decrease is of the mean freezing-point or strength. The molecular weight $m^{\prime}$ is deduced from the freezing-points in accordance with van't Hoff's formula

$$
n^{\prime}=\frac{\text { mean strength } \times 18 \cdot 9}{\text { mean f.-p. }} .
$$

The values, it will be seen, agree fairly well in most cases with the theoretical molecular weights.

The sugars as well as the tannin and dextrin were obtained from Messrs. Trommsdorf. The dextrin, however, was doubtless very far from being pure (indeed pure dextrin has never yet been obtained), and very little weight can be attached to the results obtained with it. The sample of amylodextrin I owe to the courtesy of Mr. Horace Brown : unfortunately, however, the solution used deposite $\bar{d}$ some of the substance during the experiments in the insoluble form, and hence the results with it are very doubtful; for not only is the mean strength of the solution uncertain, but the amount which had diffused out is also uncertain ; for this had to be estimated in the diffusate, a large quantity of it being evaporated to a small bulk so as to obtain a depression of freezing-point sufficient for measurement; while, to correct for solids dissolved from the dish by the liquid during its evaporation, a similar volume of water was evaporated in the same manner. The calculated molecular weiglst of the amylodextrin was obtained from the freezing-point of the initial solution, and of that entered in Table 11. The values which these gave were $2519 \cdot 4$ and $2452 \cdot 8$ respectiv ely. The results with gallic acid are equally uncertain for a similar reason, the solution taken having been too strong, and having deposited crystals during the course of the experiment.

In the case of pyrogallol the liquid used to make the solu- 
tion, and also that into which it diffused, was a very weak solution of sulphuric acid of which the freezing-point was $0^{\circ} .0441$. This prevented all but a trace of oxidation of the pyrogallol. The tannin used was probably not pure; but the difference in the calculated molecular weights deduced from the determinations in the two series is due to the solutions used being of different strengths, and to the fact that the molecular depression of the freezing-point diminishes rapidly as the strength of the solution increases. The depressions, I may mention, appear to show some marked irregularity; for when the four determinations (the two in Table I. at the initial strength, and the first two in Table II.) are plotted out, they do not all lie on any simple curve, either the determination at 12 parts to 100 giving much too small a value, or that at 16 parts too large a value. Another specimen of tannin was examined as to the freezing-points, and the results, which are the last four given in Table II., show the same peculiarity. 'This sample, however, gave throughout smaller values than that used in the diffusion-experiments, and the three stronger solutions of it deposited some tannin as well as ice in the freezing-point determination. The first sample did not do so.

In order to make the results of the first series more easily comparable with those of the second, the values for $m v^{2}$ obtained in the former have been multiplied by $2.577(=x)$, in accordance with the results obtained with glycerine and cane-sugar, as nentioned above. The values for $m v^{2}$ are, as will be seen, very far from being constant. They vary from 16.09 with pyrogallol (omitting the doubtful result; with gallic acid) to 46.81 with the weakest solution of cane-sugar; a variation of some 200 per cent., which cannot be in any way explained by the purely experimental error, since this, as has been mentioned, does not exceed 2 to 3 per cent. When we take the molecular weight deduced from the osmotic pressure (freezing-point) itself, $m^{\prime}$, instead of the theoretical molecular weight, the constancy is in inost cases scarcely improred; and, indeed, in those three cases where these calculated molecular weights do not agree with the simple theoretical weight, the values for $m^{\prime} v^{2}$ are made much less nearly constmint, and attain the enormous proportions of from 72 to 260 . This tends to show that there is a want of agreement between the values calculated for $m v^{2}$ from the depression of the freezing-point and the rate of diffusion. 


\begin{tabular}{|c|c|c|}
\hline & 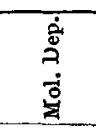 & 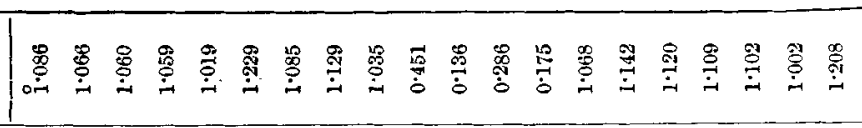 \\
\hline & है & 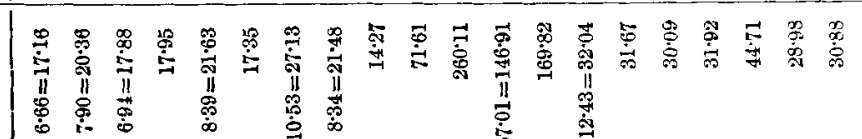 \\
\hline & 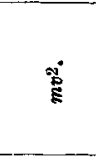 & 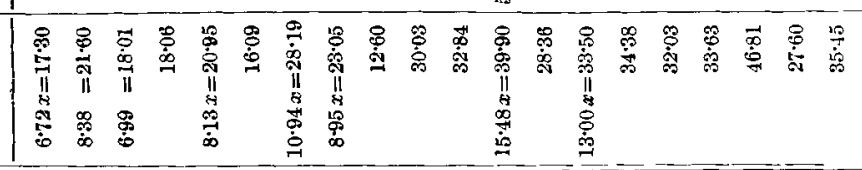 \\
\hline & 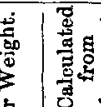 & 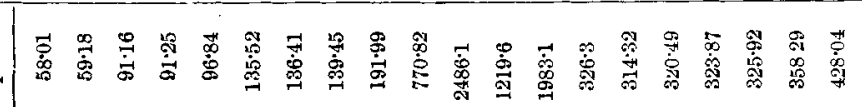 \\
\hline & 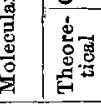 & 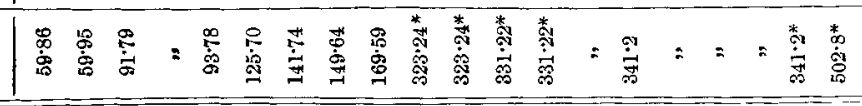 \\
\hline & 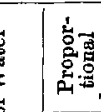 & 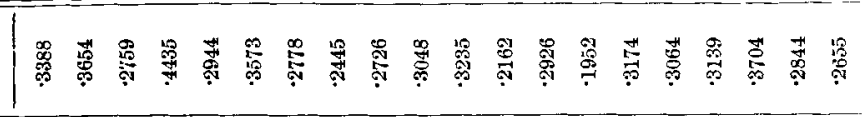 \\
\hline & 总 & 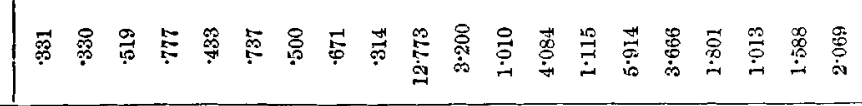 \\
\hline & 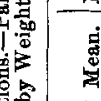 & 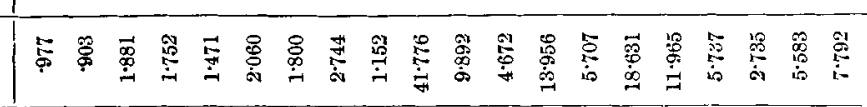 \\
\hline & 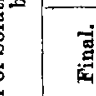 & 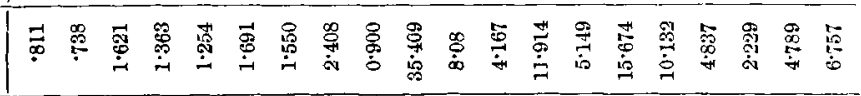 \\
\hline & 要 & 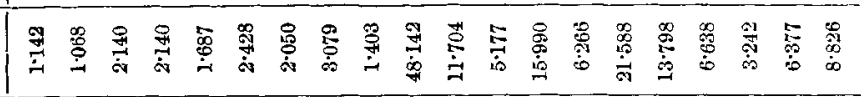 \\
\hline & 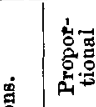 & 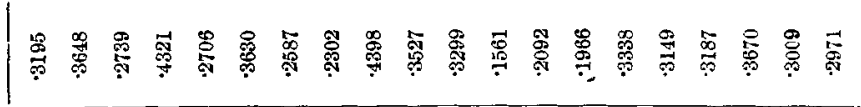 \\
\hline & ถั้ & 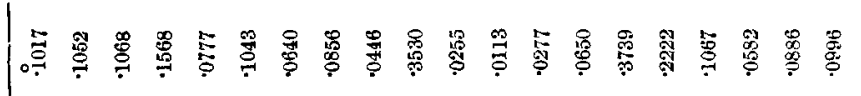 \\
\hline & 要 & 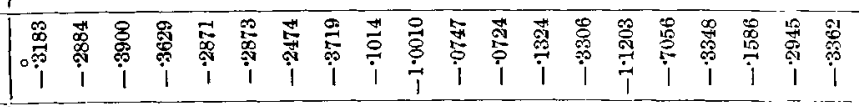 \\
\hline & 要 & 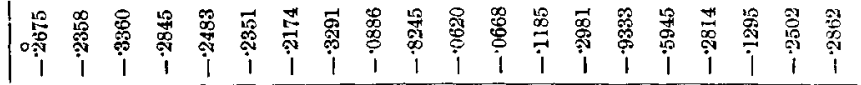 \\
\hline & & 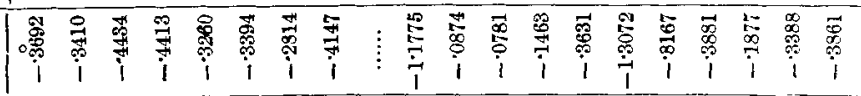 \\
\hline & 幽 & 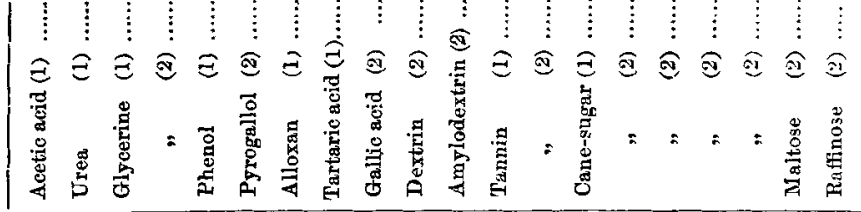 \\
\hline
\end{tabular}


TABLE II.-Supplementary Freezing-point Determinations.

\begin{tabular}{|c|c|c|c|c|c|}
\hline Substance. & $\begin{array}{l}\text { Parts to } \\
100 \text { of } \\
\text { Water. }\end{array}$ & F.-p. & Substance. & $\begin{array}{l}\text { Parts to } \\
100 \text { of } \\
\text { Water. }\end{array}$ & F.-p. \\
\hline Tartaric acid...... & $2 \cdot 152$ & $\begin{array}{r}-c \\
-.2966\end{array}$ & Dextrin ...... & $27 \cdot 484$ & - .6208 \\
\hline Alloxan ............. & $1 \cdot 425$ & -2000 & $" \quad \ldots \ldots \ldots .$. & $47 \cdot 943$ & $-1 \cdot 1082$ \\
\hline Glycerine ......... & $1 \cdot 45 \overline{3}$ & -3023 & Tannin ............ & 2557 & $-\cdot 0440$ \\
\hline Maltose ........ & $4 \cdot 670$ & -.2463 & , & $12 \cdot 310$ & - $\cdot 1221$ \\
\hline Pyrogallol .... & 1.603 & -2228 & , & $15 \cdot 804$ & -1110 \\
\hline Gallic acid.... & 0.667 & -.0697 & " & $10 \cdot 181$ & -.0814 \\
\hline " & $0 \cdot 133$ & -.0180 & $"$ & 4983 & $-\cdot 0542$ \\
\hline Raffinose .... & 0640 & -2669 & ............ & $2 \cdot 473$ & $-\cdot 0342$ \\
\hline Amylodextrin & $7 \cdot 940$ & -0609 & & & \\
\hline
\end{tabular}

The "molecular" depression, which, on the theory of osmotic pressure, will be proportional to $m v^{2}$, must, when we take the molecular weights calculated from it $\left(m^{\prime}\right)$, be an absolute constant, whereas the values for this same quantity $\left(m^{\prime} v^{2}\right)$, when deduced from the diffusion-experiments, and when these same molecular weights are used, are far from being constant; moreover, while the "theoretical" molecular weights give the values of $m v^{2}$ in the diffusion experiments with dextrin, amylodextrin, and tannin as being similar to those with the other substances investigated, they will, when used for calculating the molecular depression, give values from $\frac{1}{2}$ to $\frac{1}{8}$ th only of thuse obtained with the other substances investigated. These values are given in the last column of the table : molec. dep. $=($ mean dep. $\times m) \div($ mean strength $\times 17 \cdot 96$ ).

The fact that the results with dextrin, amylodextrin, and tannin are of doubtful accuracy must, it is true, weaken the strength of any conclusions based on them. But, on the other hand, the fact that they do not give exceptional values for $m v^{2}$ renders it probable that they are not very inaccurate; and, moreover, the exceptional values which they give for $m^{\prime} v^{2}$ are not out of harmony with the results with the other substances; for the sugars, where the moleoular weights are large, give values which are considerably larger than those given by the other substances examined. There seems indeed to be a general tendency for $m^{\prime} v^{2}$ to increase with the molecular weight of the substance diffusing : thus, with the first seven substances entered in the table we have molecular 
weights from 60 to 150 , and the value of $m^{\prime} v^{2}$ is generally about 20: with the last three substances in the table, where the molecular weights are ligh, 314 to 430 (taking the calculated values $\left.m^{\prime}\right), m^{\prime} v^{2}$ is much larger, namely over 30 ; while dextrin, tannin, and amylodextrin show still larger, and, taken in their order, increasing molecular weights, and also larger and increasing values for $m^{\prime} v^{2}$. Thus it would appear that with higher molecular weights the rate of diffusion is abnormally large.

The exceptionally large values for $m v^{2}$ in the case of the weakest solution of cane-sugar is remarkable, but in the absence of a duplicate determination it is well not to lay much stress upon it:

XVI. Contact-Action and the Conservation of Energy. By Prof. J. G. MacGregon, M.A., Sc.I).*

GEVERAL years ago Prof. O. J. I Iodge, in a series of $D$ papers published in this Magazine $\dagger$, proposed new definitions of work done and energy, and claimed (1) that by their aid he had deduced from the third law of motion and the hypothesis of universal contact-action alone, a law (which he called the law) of the conservation of energy; (2) that the law thus deduced was an extension of, and fully as axiomatic as, the law ordinarily enunciated under the same name; (3) that action at a distance might be shown to be incompatible with Newton's third law, or the law of the conservation of energy, or both; and (4) that energy cannot he transferred without being transformed, or transformed without being transferred. 'These claims, though primâ facie so extraordinary as necessarily to have drawn attention, have never, so far as I am aware, been serionsly cballenged, and it is, perhaps, somewhat late in the day to challenge them now; but the remarkable progress which has recently been made in the application of contact-action theories, seems to make it desirable that they should be subjected to examination.

(1) The Deduction of the Conservation of Energy.

In the first version of the argument by which this dednction is made $\ddagger$, Prof. Lodge seems to me (a) to assume the ordinary law of the conservation of energy in addition to the third law

* Communicated by the Author.

+ Phil. Mag. [5] vols. viii. (1879) p. 277, xi. (1881) pp. $36 \& 529$, xix. (1885) p. 482 .

\pm Ibid. vol. viii. (1879) p. 278. 